\title{
The nuclear receptor steroidogenic factor 1 acts at multiple levels of the reproductive axis
}

\author{
Holly A. Ingraham, ${ }^{1,2}$ Deepak S. Lala, ${ }^{3}$ Yayoi Ikeda, ${ }^{3}$ Xunrong Luo, ${ }^{4}$ Wen-Hui Shen, ${ }^{2}$ \\ Mark W. Nachtigal, ${ }^{2}$ Rula Abbud, ${ }^{5}$ John H. Nilson, ${ }^{5}$ and Keith L. Parker ${ }^{3,6}$ \\ Departments of ${ }^{1}$ Physiology and ${ }^{2}$ Reproductive Sciences, University of California at San Francisco, San Francisco, California \\ 94143-0556 USA; ${ }^{3}$ Howard Hughes Medical Institute and the Departments of Medicine and Pharmacology or ${ }^{4}$ Department \\ of Biochemistry, Duke University Medical Center, Durham, North Carolina 27710 USA; ${ }^{5}$ Department of Pharmacology, \\ Case Western Reserve University, Cleveland, Ohio 44106 USA
}

Steroidogenic factor 1 (SF-1), an orphan nuclear receptor, regulates the enzymes that produce sex steroids, and disruption of the Ftz-F1 gene encoding SF-1 precludes adrenal and gonadal development. We now study the role of SF-1 at other levels of the hypothalamic/pituitary/gonadal axis. In Ftz-F1-disrupted mice, immunohistochemical analyses with antibodies against pituitary trophic hormones showed a selective loss of gonadotrope-specific markers, supporting the role of SF-1 in gonadotrope function. In situ hybridization analyses confirmed these results; pituitaries from Ftz-F1-disrupted mice lacked transcripts for three gonadotrope-specific markers ( $\mathrm{LH} \beta, \mathrm{FSH} \beta$, and the receptor for gonadotropin-releasing hormone), whereas they exhibited decreased but detectable expression of the $\alpha$-subunit of glycoprotein hormones. SF- 1 transcripts in the developing mouse pituitary, which first became detectable at embryonic day 13.5-14.5, preceded the appearance of FSH及 and LHß transcripts. In adult rat pituitary cells, SF-1 transcripts colocalized with immunoreactivity for the gonadotrope-specific LH. Finally, SF-1 interacted with a previously defined promoter element in the glycoprotein hormone $\alpha$-subunit gene, providing a possible mechanism for the impaired gonadotropin expression in Ftz-F1-disrupted mice. These studies establish novel roles of this orphan nuclear receptor in reproductive function.

[Key Words: Nuclear receptor SF-1; reproductive function; gonadal development]

Received May 31, 1994; revised version accepted August 15, 1994.

Gonadal steroids play essential roles in reproduction. Their biosynthesis in the ovary and testis is regulated by complex interactions within the hypothalamic/pituitary/gonadal axis. The predominant regulators of steroidogenesis in gonadal cells are the pituitary gonadotropins, follicle-stimulating hormone (FSH), and luteinizing hormone $(\mathrm{LH})$, which are secreted by gonadotropes in the anterior pituitary. Both mature hormones are heterodimeric glycoproteins containing a common polypeptide, the $\alpha$-glycoprotein hormone subunit $(\alpha \mathrm{GSU})$, and unique FSH $\beta$ or LH $\beta$ polypeptide chains (Pierce and Parsons 1981). Gonadotropin release is regulated in turn by gonadotropin-releasing hormone (GnRH), which is produced by neurons in the medial basal hypothalamus and secreted into the hypophyseal plexus in response to various stimuli (Schwanzel-Fukuda et al. 1992). A complex interplay of gonadal steroids, peptides (e.g., activin and inhibin), and binding proteins (e.g., follistatin) mediates feedback regulation at both the hypothalamus and pitu-

${ }^{6}$ Corresponding author. itary, altering the overall levels and pattern of gonadotropin release (Gharib et al. 1990).

Development of steroidogenic organs has been shown recently to require an orphan nuclear receptor, designated steroidogenic factor 1 (SF-1), or adrenal 4-binding protein (Lala et al. 1992; Honda et al. 1993). In adult mice, SF-1 is predominantly expressed in the adrenal gland, testis, and ovary, where it regulates the coordinate expression of the cytochrome P-450 steroid hydroxylases (Ikeda et al. 1993). In mouse embryos, SF-1 is found in adrenal and gonadal tissues from their earliest stages of organogenesis (Ikeda et al. 1994). The observed expression of SF-1 in the fetal Leydig cells, which produce androgens, is consistent with its role in regulating the steroidogenic enzymes. We also observed SF-1 expression in fetal Sertoli cells, which produce Müllerian inhibiting substance [(MIS) Ikeda et al. 1994]. A possible rationale for the expression of SF-1 by fetal Sertoli cells came when we implicated SF-1 as an important regulator of the MIS gene (Shen et al. 1994). It thus appears that SF-1 regulates both hormones that are essential for male sexual differentiation: androgens and MIS. Our analyses 
also revealed high levels of SF-1 transcripts in the embryonic ventral diencephalon (Ikeda et al. 1994), which gives rise to part of the hypothalamus. Taken together, these observations suggested that the role of SF-1 in reproductive function extends well beyond regulating the enzymes that make gonadal steroids.

To assess directly the role of SF-1 in vivo, we prepared mice with homozygous disruption of the Ftz-F1 gene, which encodes both SF-1 and a related isoform, the embryonal long terminal repeat binding protein (ELP) (Tsukiyama et al. 1992; Ikeda et al. 1993). All Ftz-F1disrupted animals lacked adrenal glands and gonads and had female internal genitalia (Luo et al. 1994). Analysis of staged Ftz-F1-disrupted mouse embryos showed that the gonads initially developed normally but then regressed by programmed cell death (Luo et al. 1994). These findings established the essential role of this gene in steroidogenic organ development and sexual differentiation.

The key role of SF-1 in steroidogenic organ development and its expression in the embryonic diencephalon suggested additional studies to define the function of SF-1 at the level of the hypothalamus and pituitary. In this report we show that the pituitaries of Ftz-F1-disrupted mice lack detectable $\mathrm{LH}, \mathrm{FSH}$, and GnRH receptor-three gonadotrope-specific markers. We show further that SF-1 is expressed both in normal gonadotropes and in an immortalized gonadotrope cell line, where it interacts with a regulatory element in the $\alpha \mathrm{GSU}$ promoter. Our results demonstrate that SF-1 acts at multiple levels of the reproductive axis to permit reproductive competence.

\section{Results}

The pituitary glands of Ftz-F1-disrupted mice lack gonadotrope-specific markers

Based on our previous developmental studies showing that SF-1 is expressed at high levels in a region of the embryonic diencephalon that gives rise to the endocrine hypothalamus (Ikeda et al. 1994), we evaluated the effects of Ftz-F1 disruption at other levels of the reproductive axis. Immunohistochemical analyses of pituitary sections with a panel of antibodies against pituitary trophic hormones revealed a selective deficiency of gonadotrope-specific proteins, with no detectable staining with either the anti-LH or anti-FSH antibodies (Fig. 1A,B). In contrast, Ftz-F1-disrupted and wild-type animals showed comparable staining with antibodies against five other pituitary proteins (Fig. 1C-G): Thyroid-stimulating hormone (TSH) expressed in thyrotropes; growth hormone, expressed in somatotropes; prolactin, expressed in lactotropes; adrenocorticotropic hormone (ACTH) expressed in corticotropes; and Pit-1, a transcription factor expressed in cells of the somatotrope, lactotrope, and thyrotrope lineages. The patterns of staining matched the known intracellular locations of the various proteins, with a nuclear distribution of Pit-1 protein and a cytoplasmic localization of the hormones.
Radioimmunoassays for growth hormone confirmed the immunohistochemistry results, showing that circulating growth hormone levels did not differ significantly between Ftz-F1-disrupted and wild-type mice /data not shown). The absence of gonadotropins in the Ftz-F1-disrupted mice suggests a role for SF-1 in normal pituitary gonadotrope development and/or gene expression.

Next, we performed in situ hybridization analyses with cRNA probes specific for several genes that are expressed in the pituitary. As shown in Figure 2A, proopiomelanocortin (POMC) transcripts, which encode the precursor of $\mathrm{ACTH}$, were expressed in the Ftz-F1-disrupted mice at levels at least the equal of those seen in wild-type mice. In contrast, analyses with a probe specific for the $\alpha \mathrm{GSU}$ revealed lower, but clearly detectable, levels in the Ftz-F1-disrupted mice (Fig. 2B). Given that $\alpha G S U$ is normally expressed in two pituitary cell types, the gonadotropes and thyrotropes, this finding is consistent with the absence of $\alpha$ GSU expression in the gonadotropes with persistent expression at normal levels in the thyrotropes. Consistent with the absence of LH and FSH immunoreactivity, and at a time when they were clearly detected in wild-type littermates, $\mathrm{LH} \beta$ and FSH $\beta$ transcripts were absent from pituitary sections taken from the Ftz-F1-disrupted animals (Fig. 2C,D).

Because $\mathrm{LH} \beta$ and $\mathrm{FSH} \beta$ are coordinately regulated in gonadotropes and presumably derive from a common ancestral gene (Gharib et al. 1990), we also analyzed levels of transcripts for the GnRH receptor, another gonadotrope-specific marker that shares no structural homology with the gonadotropin $\beta$ subunits. As revealed by both in situ hybridization (Fig. 3A) and RNase protection assays (Fig. 3B), pituitary expression of the GnRH receptor in Ftz-F1-disrupted mice was undetectable when expression was readily detected in wild-type littermates. In the RNase protection assays, $\beta$-actin expression was comparable in the $+/-$ and $-/$ - RNA samples, documenting the integrity of the pituitary RNA from the $-/-$ mice. These studies thus indicate that the Ftz-F1-disrupted mice are deficient in their expression of three separate gonadotrope-related genes, demonstrating a clear link between Ftz-F1 (presumably via SF-1) and gonadotrope function.

\section{SF-1 expression during pituitary development temporally precedes the onset of FSH $\beta$ and LH $\beta$ expression}

Previous studies have defined the order in which the markers of different pituitary lineages first appear during development. In the mouse, the onset of expression of the $\alpha \mathrm{GSU}$, which first becomes detectable on embryonic day 12.5 (E12.5), precedes that of FSH $\beta$ and $\mathrm{LH} \beta$, which are not detected until after E16.5 (Japon et al. 1994). Prompted by the finding that the absence of SF-1 markedly impairs gonadotropin expression, we analyzed the developmental profile of SF-1 transcripts. We did not detect expression in the region of the developing pituitary in any embryos at E12.5 or earlier (data not shown). A faint signal of SF-1 expression in the region of the devel- 
Figure 1. Ftz-F1-disrupted animals are selectively deficient in gonadotropin expression. Pituitary glands from Ftz-F1-disrupted or wild-type littermates were isolated and analyzed by immunohistochemical staining with antibodies against pituitary trophic hormones and Pit-l as described in Materials and methods. Representative regions of coronal sections are shown. Bar, $50 \mu \mathrm{m}$. (A) Anterior lobe of the pituitary; $(\mathrm{I})$ intermediate lobe; $(\mathrm{P})$ posterior lobe; ( $\mathrm{LH})$ luteinizing hormone; (FSH) follicle-stimulating hormone; (TSH) thyroid-stimulating hormone; $(\mathrm{GH})$ growth hormone; (PRL) prolactin; $(A C T H)$ adrenocorticotrophic hormone.

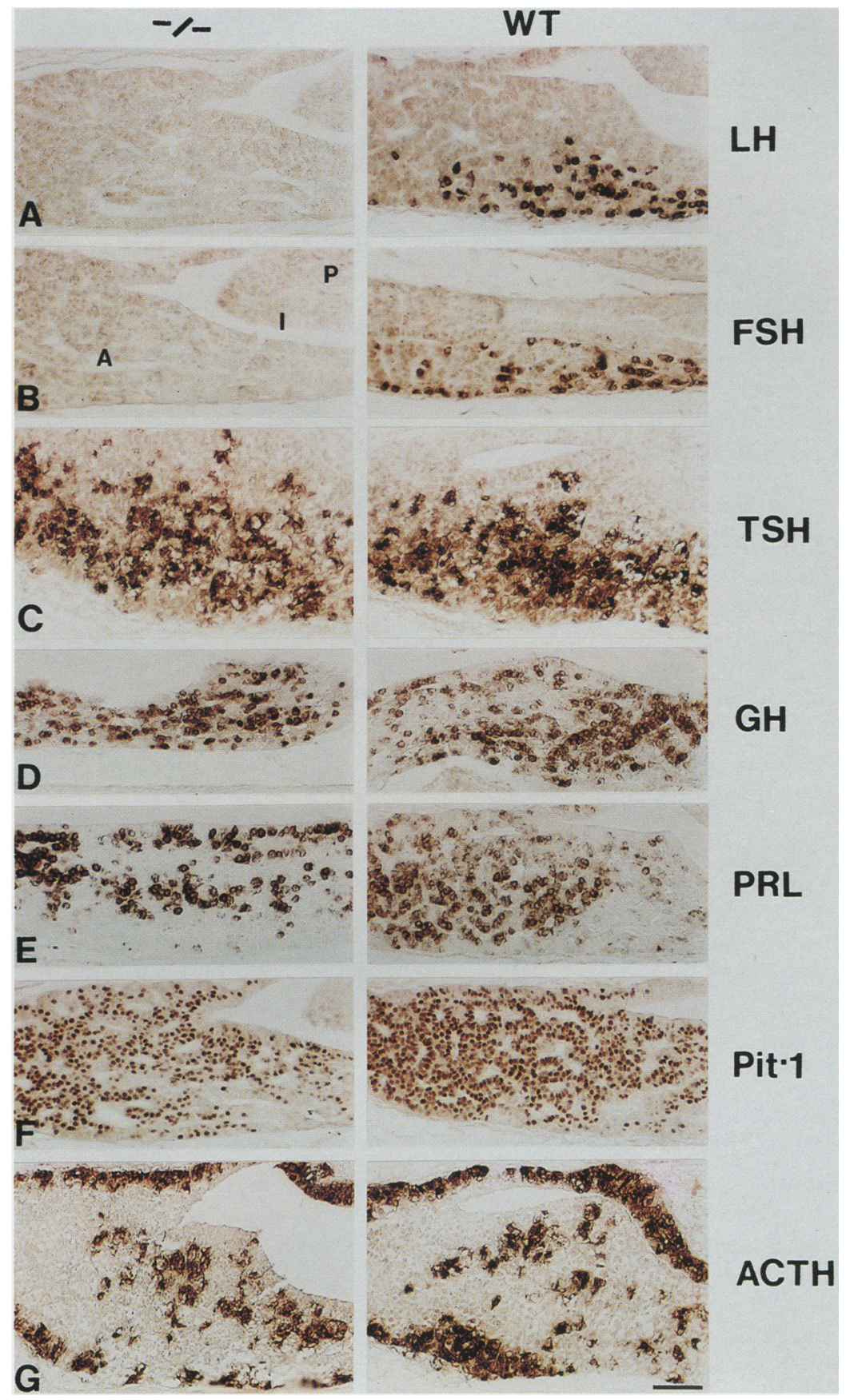

oping anterior pituitary was first detected at E13.5 (Fig. 4). By E14.5, increased levels of SF-1 transcripts were readily detected, with even higher levels at E17.5. Thus, SF-1 is first expressed after the initiation of $\alpha$ GSU expression, indicating that SF-1 is not an obligatory regulator of the $\alpha G S U$ gene at early stages of pituitary development. In contrast, the expression of SF- 1 clearly antedates the onset of expression of both $\mathrm{LH} \beta$ and $\mathrm{FSH} \beta$ (Japon et al. 1994), consistent with the model that SF-1 regulates their expression directly or indirectly. Similar results were obtained using RNase protection assays with RNA from rat pituitaries: $\alpha$ GSU expression, which in the rat begins at $\sim$ E12.5, preceded the first detectable expression of SF-1 at E14.5, and SF-1 expression, in turn, preceded the onset of $\mathrm{LH} \beta$ and $\mathrm{FSH} \beta$ expression at E16.5 (Simmons et al. 1990; H. Ingraham, unpubl.).

SF-1 protein is expressed in the pituitary gland To determine whether SF-1 transcripts detected by in situ hybridization accurately reflected levels of SF-1 protein, we sought to demonstrate SF-1 protein in the pituitary. Because our polyclonal antiserum directed against the 

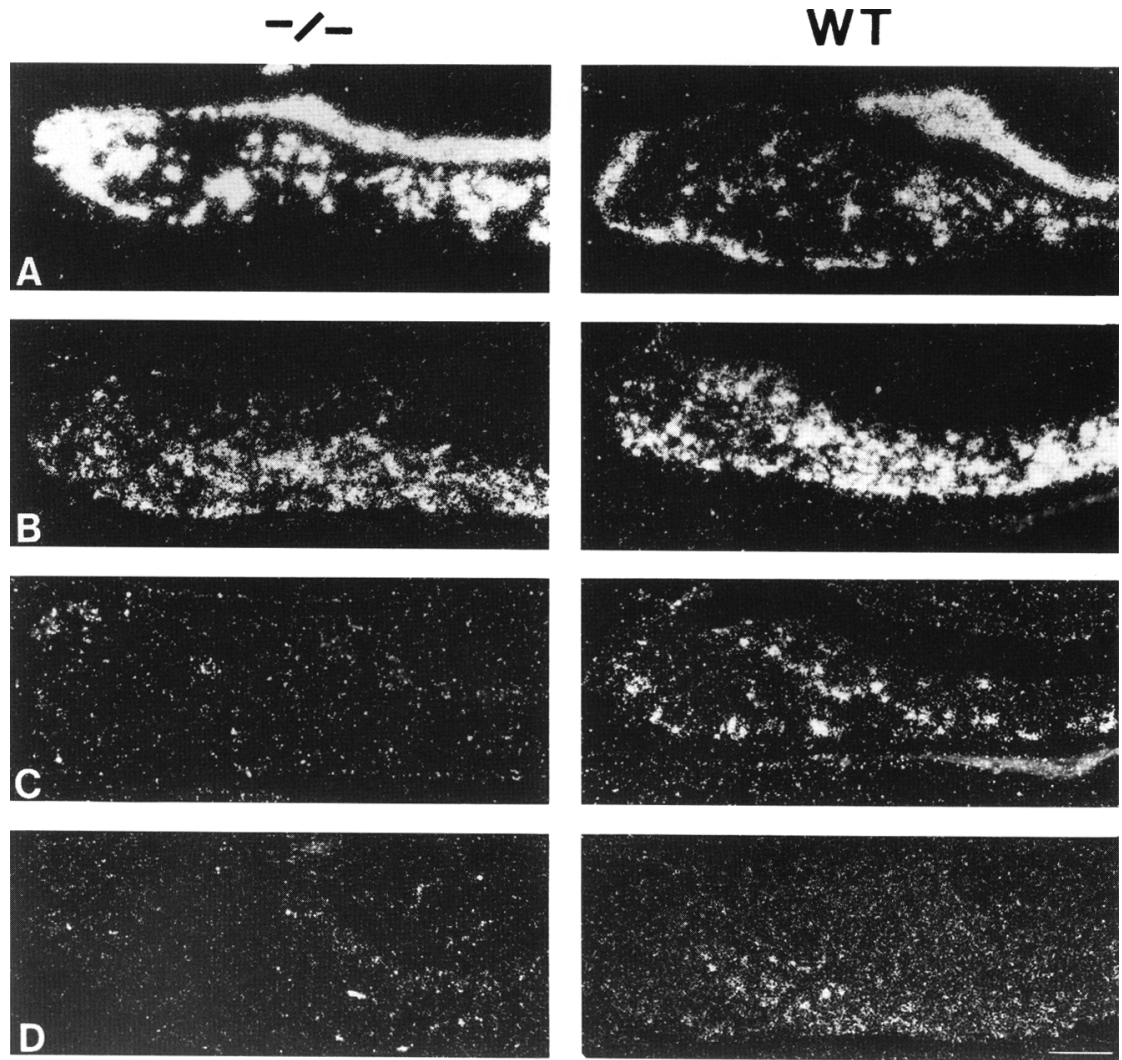

Figure 2. Expressions of mRNAs for the $\alpha \mathrm{GSU}, \mathrm{LH} \beta$, and FSH $\beta$ are diminished in newborn Ftz-F1-disrupted animals. Pituitary coronal sections from Ftz-F1-disrupted and wild-type littermates were analyzed by in situ hybridization as described in Materials and methods. $|A|$ POMC; $(B) \alpha G S U ;(C)$ FSH $\beta$; $(D)$ LH $\beta$. Bar, $100 \mu \mathrm{m}$.
DNA-binding domain of SF-1 (Ikeda et al. 1993) proved inadequate for immunohistochemical analyses of mouse pituitary sections, we instead used this anti-SF-1 antiserum in immunoblotting analyses of rat pituitary extracts. As shown by the presence of a $54-\mathrm{kD}$ protein (Fig. 5 ), SF-1 protein is present in rat pituitary extracts but not in extracts derived from rat kidneys. The signal in immunoblotting analyses was corroborated by gel mobility retardation assays, in which both testis and pituitary extracts formed a prominent complex with a probe containing the recently described SF-1 recognition site from the rat MIS gene (Shen et al. 1994). This complex was not formed by kidney extracts and was specifically abolished by preincubation with the anti-SF-1 antiserum (Fig. 5), providing strong evidence that SF-1 protein is expressed in the pituitary. It should be noted that levels of SF-1 protein in the rat pituitary are considerably lower than those seen in adrenal glands or testes, suggesting either that pituitary cells express lower levels of SF-1 or that SF-1 expression is limited to a subset of pituitary cells.

SF-1 is selectively expressed in gonadotropes The selective effect of $F t z-F 1$ disruption on gonadotropin expression and the demonstration that SF-1 protein is expressed in the pituitary suggested that SF-1 is expressed in gonadotropes. To test this model, we first examined SF-1 expression in pituitary cell lines derived from the various cell lineages that retain some aspects of their differentiated function. Using RNase protection assays
(Fig. 6), we found SF-1 transcripts only in the gonadotrope-derived cell line $\alpha \mathrm{T} 3-1$. This cell line, created by using the $5^{\prime}$-flanking region of $\alpha G S U$ to target transgenic expression of the SV40 T antigen, binds GnRH via the GnRH receptor but expresses neither LH $\beta$ nor FSH $\beta$-subunits (Windle et al. 1990). In contrast, no SF-1 transcripts were detected in RNA isolated from a hypothalamic cell line expressing GnRH (GT-1) (Mellon et al. 1990) or in other pituitary cell lines representative of thyrotropes ( $\alpha$ TSH) (Akerblom et al. 1990), the combined somatotropes/lactotropes (GC), or lactotropes (235-1). In addition, SF-1 was not present in mRNA isolated from the corticotrope cell line, AtT-20 (data not shown).

Immunoblotting analysis with the anti-SF-1 antiserum confirmed that SF-1 protein is present in $\alpha \mathrm{T} 3-1$ cells (Fig. 5). Gel mobility retardation assays with a known SF-1-binding site from the steroid 21-hydroxylase gene supported this finding; $\alpha \mathrm{T} 3$ extracts produced a prominent complex that migrated identically to the complex seen with Yl adrenocortical extracts (Fig. 6). This complex migrated identically to that formed by SF-1 produced by in vitro transcription and translation, indicating that SF-1 is very likely the only protein involved in its formation (data not shown). Moreover, in competition experiments with oligonucleotides containing progressive 2-bp mutations of the 21-hydroxylase -140 element, the $\alpha \mathrm{T} 3$ protein required the bases CCAAGGCT for efficient binding, matching exactly the binding profile of SF-1 from Y1 adrenocortical cells. Collectively, 
A
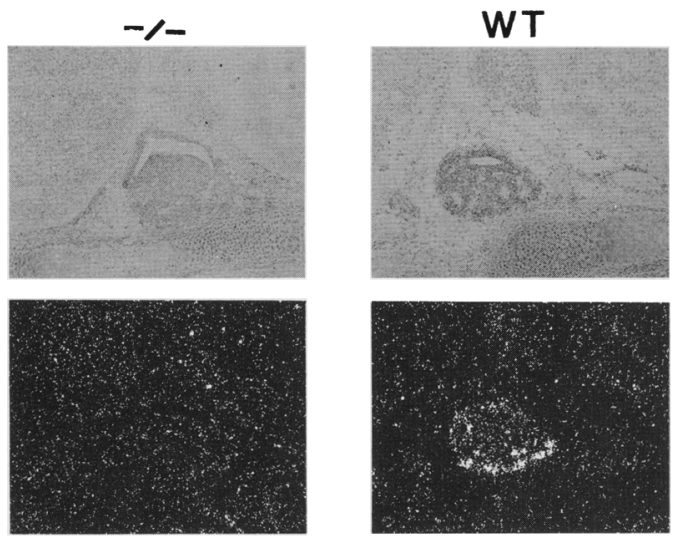

B

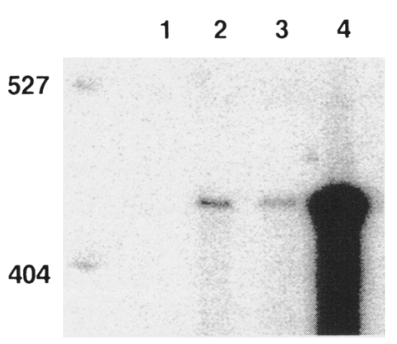

GnRH receptor
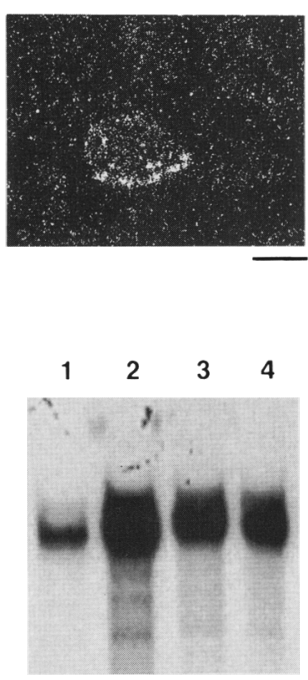

B-Actin $\begin{array}{llll}1 & 2 & 3 & 4\end{array}$

Figure 3. GnRH receptor transcripts are undetectable in FtzF1-disrupted animals. (A) In situ hybridization analyses. Pituitary sagittal sections from Ftz-F1-disrupted and wild-type E17.5 littermates were analyzed by in situ hybridization with the GnRH receptor probe as described in Materials and methods. The scale bar equals $200 \mu \mathrm{m}$. $(B)$ RNase protection assay of GnRH receptor mRNA levels. Total RNA was prepared and RNase protection assays were performed as described in Materials and methods. The protected fragment of the mouse GnRH receptor probe was 434 nucleotides; the size of the intact probe was 534 nucleotides. (Lane 1) $-/-$ Pituitary RNA; (lane 2) $+/$ - pituitary RNA; (lane 3) +/+ pituitary RNA; (lane 4) $\alpha \mathrm{T} 3$ gonadotrope RNA. The positions of size markers are indicated at left. (Right) An assay performed with a mouse $\beta$-actin probe. (Lane 1) Mouse liver RNA; (lane 2) $\alpha$ T3 gonadotrope RNA; (lane 3) $+/$ - pituitary RNA; (lane 4$)-/$ - pituitary RNA.

these studies show that SF-1, or an immunologically related protein with an identical DNA-binding specificity, is expressed in pituitary gonadotropes but not in other pituitary cell lines.

The $\alpha \mathrm{T} 3$ cells are transformed and fail to exhibit important characteristics of gonadotrope function such as LH and FSH expression. We therefore compared the patterns of expression of SF-1 and gonadotrope-specific markers in normal pituitary cells. As shown in Figure $7 \mathrm{~A}$, the distribution of SF-1 transcripts in the adult mouse pituitary closely corresponded to the patterns of both FSH $\beta$ and $L H \beta$, suggesting that the same cell type (i.e., gonadotropes) expressed all three probes. More definitive support for this model came from combined immunohistochemistry/in situ hybridization analyses per-

formed with primary cultures of rat pituicytes. These experiments (Fig. 7B) clearly showed localization of silver grains representing hybridization to SF-1 mRNA within the darkly labeled cells containing immunoreactive LH. Collectively, these studies show unambiguously that SF-1 is expressed by both SV40-transformed and normal gonadotropes.

SF-1 interacts with the gonadotrope-specific element Previous studies using $\alpha \mathrm{T} 3$ cells identified a conserved promoter element in the $5^{\prime}$-flanking region of the human $\alpha G S U$ gene that interacts with a gonadotrope-specific, 54-kD protein (Horn et al. 1992). This promoter element contains an AGGTCA motif matching the known requirements for SF-1 binding (Lala et al. 1992; Morohashi et al. 1992), suggesting that the $54-\mathrm{kD}$ protein may be SF-1. We therefore performed gel mobility retardation assays with radiolabeled gonadotrope-specific element (GSE) and nuclear extracts derived from Y1 adrenocortical, MA-10 Leydig, and $\alpha \mathrm{T} 3$ gonadotrope cell lines, as well as several other control cell lines. As shown in Figure 8 , indistinguishable complexes were formed by nuclear extracts from Yl adrenocortical, MA-10 Leydig, and $\alpha \mathrm{T} 3$ gonadotrope cells. In addition, the complex formed by nuclear extracts from $\alpha \mathrm{T} 3$ cells was inhibited by pretreatment with the anti-SF-1 antiserum or by unlabeled oligonucleotide competitors containing the sequences of two known SF-1 responsive elements (Fig. 8; $-140,-210$ ) from the steroid 21-hydroxylase gene (Rice et al. 1991). These findings show that SF-1 is the protein in $\alpha \mathrm{T} 3$ cells that binds the GSE and suggest that SF-1 may interact with this element to regulate $\alpha$ GSU expression in gonadotropes.

\section{Discussion}

Mammalian reproductive function is regulated by the hypothalamic/pituitary/gonadal axis. We demonstrate here that the nuclear receptor SF-1 is essential for expression of three gonadotrope-specific markers in the pituitary. This finding, combined with the previous observations that SF-1 is essential for gonadal development and function (Ikeda et al. 1994; Luo et al. 1994), implicates SF-1 as a key regulator at multiple levels of reproduction.

The selective loss of gonadotropin expression in FtzF1-disrupted mice and the presence of SF-1 in $\alpha \mathrm{T} 3$ cells and primary gonadotropes suggest that SF- 1 in the pituitary is expressed exclusively in gonadotropes. The relatively low level of SF-1 expression observed by in situ analysis is consistent with this, as gonadotropes constitute $<10 \%$ of cells in the anterior pituitary (Thorner et al. 1992). The dramatic effects of Ftz-F1 disruption on gonadotrope function most likely reflect either direct actions of SF-1 in gonadotropes or indirect effects that are exerted in the hypothalamus. Within the pituitary, two mechanisms may account for the observed absence of gonadotropin expression in the Ftz-F1-deficient mice: either SF-1 is required to establish the gonadotropic lin- 

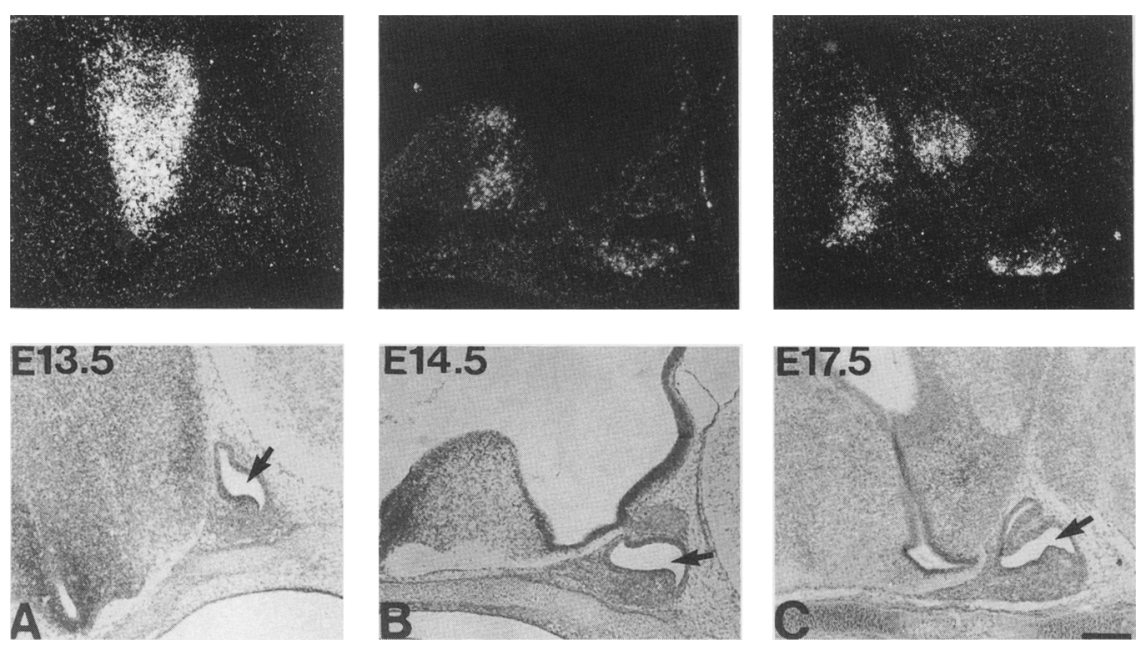

Figure 4. Pituitary expression of SF-1 begins before $\mathrm{LH} \beta$ and $\mathrm{FSH} \beta$ are expressed. Sagittal sections of mouse embryos at the indicated stages of development were prepared as described in Materials and methods and hybridized with the SF-1 probe. Bright-field (bottom) and dark-field (top) views are shown. The arrow indicates the region of the developing pituitary gland. Bar, $200 \mu \mathrm{m}$. eage and/or SF-1 directly regulates the expression of multiple genes required for gonadotropin expression.

At this time, we cannot distinguish between these alternatives. The reduced $\alpha G S U$ expression in Ftz-F1-disrupted mice and the finding that SF-1 binds a promoter element proposed to regulate $\alpha G S U$ expression suggest that SF- 1 directly regulates the $\alpha G S U$ gene, and by analogy, the LH $\beta, F S H \beta$, and GnRH receptor genes. However, the precise role of the GSE site in $\alpha$ GSU expression remains undefined. Transfection experiments using $\alpha \mathrm{T} 3$ cells suggest that the GSE is important for $\alpha G S U$ expression (Horn et al. 1992). Moreover, the GSE lies within the proximal 313 -bp region of 5 '-flanking sequences shown to direct gonadotrope-specific expression in transgenic targeting experiments (Kendall et al. 1991; Hamernik et al. 1992). However, it is unclear whether the GSE-SF-1 interaction fully accounts for gonadotrope-specific expression in vivo, as mutations of the GSE in transfection studies result in relatively small diminutions in expression of reporter genes (Horn et al. 1992; J. Nilson, unpubl.). Full levels of $\alpha G S U$ expression likely depend on combinatorial regulation, and other promoter elements almost certainly contribute to its expression. One such element recently implicated in pituitary $\alpha G S U$ expression interacts with the LH-2 LIM-homeodomain factor (Roberson et al. 1994).

Given that pituitary SF-1 transcripts first appear slightly before the onset of expression of $L H \beta$ and FSH $\beta$ and that $F t z-F 1$-disrupted mice lack LH $\beta$ and FSH $\beta$ expression, SF-1 may also directly regulate the LH $\beta$ and $\mathrm{FSH} \beta$ genes. To date, no studies have implicated potential SF-1-binding sites in the regulation of the $\mathrm{LH} \beta$ and FSH $\beta$ promoters. The absence of such sites, if supported in subsequent studies, would argue that SF-1 effects on $\beta$-subunit expression are indirect, or alternatively, that SF-1 is necessary for development of the gonadotrope cell lineage.

Is SF-1 directly required for development of the gonadotropes in the pituitary? Precedence exists for dual involvement of a single transcription factor in development of specific pituitary cells types and expression of cell-specific markers. Pit-1 (GHF-1) is directly impli-
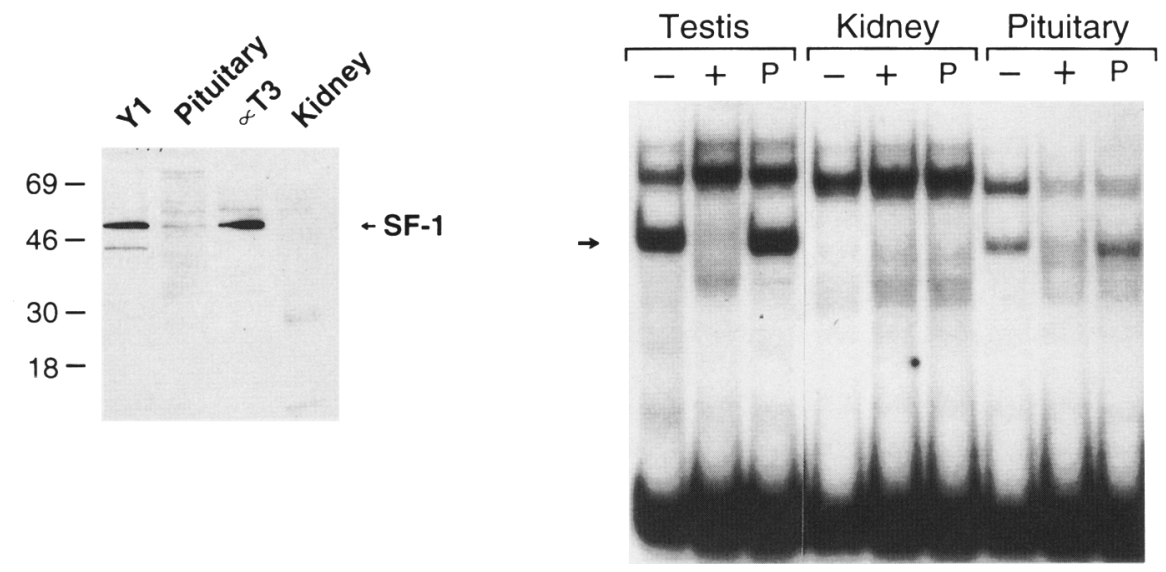

Figure 5. Pituitary glands contain SF-1 protein. Rat pituitaries were isolated and nuclear extracts were prepared as described in Materials and methods. (Left) Immunoreactive SF- 1 is expressed in the rat pituitary. Immunoblotting analyses of rat pituitary extracts from P20 rats (Pituitary/ were performed as described in $\mathrm{Ma}$ terials and methods. The arrow indicates the immunoreactive, $54-\mathrm{kD}$ pituitary protein that migrates identically to authentic SF-1 from Y1 adrenocorticol cell extract (Y1) and in extracts from the gonadotrope cell line, $\alpha \mathrm{T} 3-1$ ( $\alpha \mathrm{T} 3)$. (Right) Anti-SF-1 abrogates the complex formed with the pituitary extracts. Equivalent amounts of extracts ( $3 \mu \mathrm{g}$ of protein) were reacted alone $(-)$, with a specific anti-SF-1 antiserum $(+1$, or with preimmune serum $(\mathrm{P})$ as described in Materials and methods. The specific SF-1-DNA complex is indicated $\rightarrow 1$. 

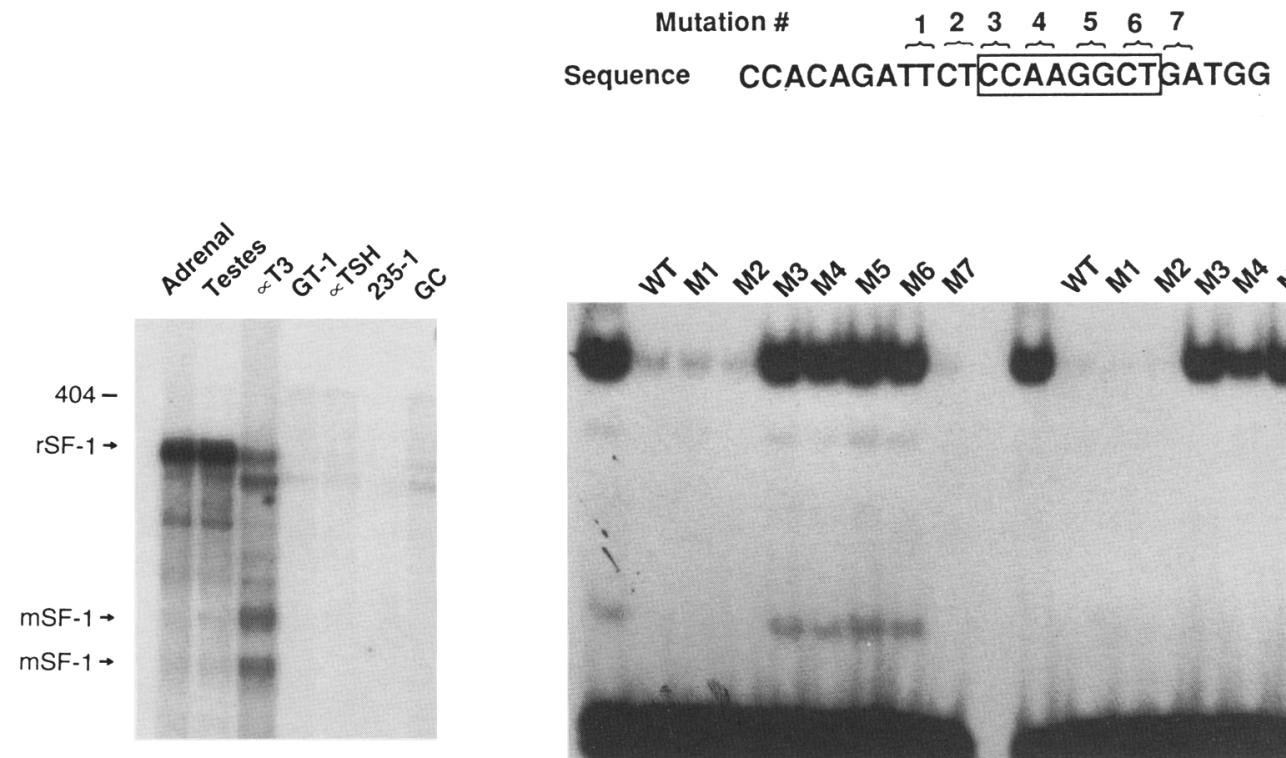

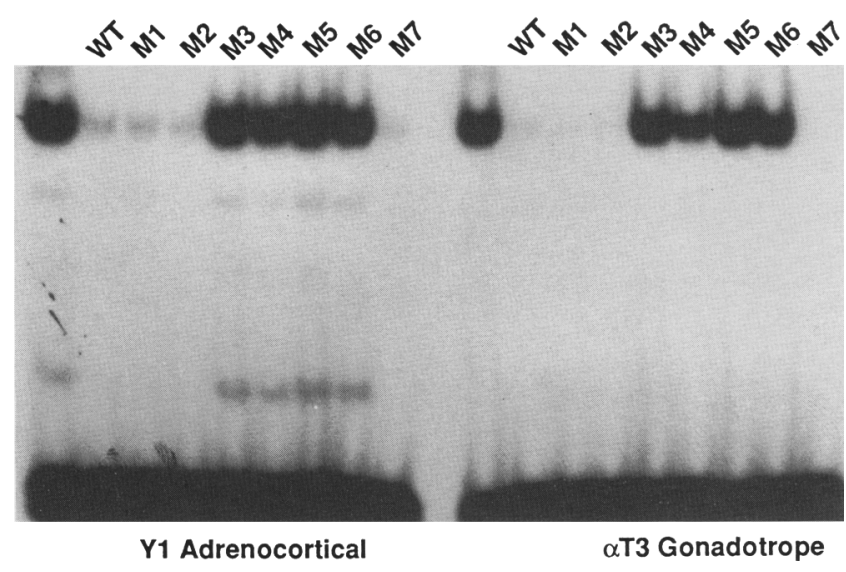

Figure 6. $\alpha \mathrm{T} 3$ gonadotropes contain SF-1. (Left) RNase protection assays were carried out as described in Materials and methods. Samples include control rat adrenal and testes RNA from P0 rats and the mouse $\alpha$ T3-1 cell line $(\alpha \mathrm{T} 3)$, the mouse GT-1 hypothalamic cell line (GT-1), mouse $\alpha$ TSH thyrotrope cell line $(\alpha \mathrm{TSH})$, the rat 235-1 prolactinoma cell line (235-1), and the rat somatomammotrope cell line (GC). Protection patterns using rat vs. mouse RNA are indicated by arrows. (Right) Demonstration that the $\alpha$ T3 protein has an identical binding specificity to SF-1 in Y1 adrenocortical cells. Gel mobility retardation assays were performed with the 21 hydroxylase -140 probe, a known high-affinity SF-1-binding site, and nuclear extracts from Y1 adrenocortical and $\alpha$ T3 gonadotrope cells. Where indicated, either wild-type unlabeled competitor or various mutated competitors containing 2-base alterations of the wild-type sequence were included. The bases altered in the various mutated competitors are shown (top); those bases essential for binding are boxed.

cated in the development and function of three pituitary cell types: somatotropes, lactotropes, and thyrotropes (Bodner et al. 1988; Ingraham et al. 1988; for review, see Voss and Rosenfeld 1992; Theill and Karin 1993). Certain natural mutations of Pit-1 lead to pituitary hypoplasia and deficiency of all three cell types ( $\mathrm{Li}$ et al. 1990), whereas other mutations affect somatotropes and lactotropes without impairing thyrotrope function and, thus, are not associated with marked pituitary hypoplasia (Pfäffle et al. 1992). Loss of SF-1, like Pit-1, has been shown to result in the loss of progenitor cells in adrenals and gonads by programmed cell death (Luo et al. 1994). Further analysis of pituitaries within these Ftz-F1-disrupted mice may reveal a similar loss of the gonadotrope lineage. Alternatively, it remains possible that cells derived from the gonadotrope lineage persist in the pituitaries of the knockout mice but are unable to express known markers of gonadotrope function, including gonadotropins. Distinguishing between these possibilities may ultimately require the isolation of additional markers of gonadotrope lineage that are not directly regulated by SF-1. In this regard, the finding that GnRH receptor expression is also impaired in Ftz-F1-disrupted mice (Fig. 3) suggests that such markers may be difficult to identify.

The expression of SF-1 in the ventral diencephalon, which ultimately contributes to the endocrine hypothalamus, suggests a direct or indirect role for SF-1 in the
GnRH hypothalamic neurons (Ikeda et al. 1994). Thus, it is attractive to propose that SF-1 acts at all three levels of the hypothalamic/pituitary/gonadal axis. We have not yet identified the specific hypothalamic cells expressing SF-1 and do not know whether SF-1 is found in GnRH neurons. To the extent that the GT- 1 cell line accurately reflects GnRH neuron function, their lack of SF-1 expression suggests that GnRH neurons do not express SF-1. It remains possible that SF-1 is normally present in GnRH neurons but that GT-1 cells lack the full repertoire of differentiated functions in a manner akin to other immortalized cell lines generated by transgenic targeting of SV40 large T oncoprotein (Windle et al. 1990; Lew et al. 1993; Peschon et al. 1992). If SF-1 does act primarily at the level of the hypothalamus to affect gonadotrope function, then it may be possible to rescue gonadotropin expression in Ftz-F1-disrupted mice. Similar GnRH rescue studies have been successful in the hypogonadal mouse, which has gonadotrope defects secondary to a mutation in the GnRH gene /Charlton et al. 1983; Mason et al. 1986).

The phenotype of the Ftz-F1-disrupted mice includes both adrenal/gonadal hypoplasia and selective deficiency of gonadotropin expression. Intriguingly, a very similar clinical presentation is seen in a subset of human patients with X-linked adrenal hypoplasia, who also have decreased gonadotropins and gonadal dysfunction in combination with adrenal hypoplasia (Kletter et al. 
A
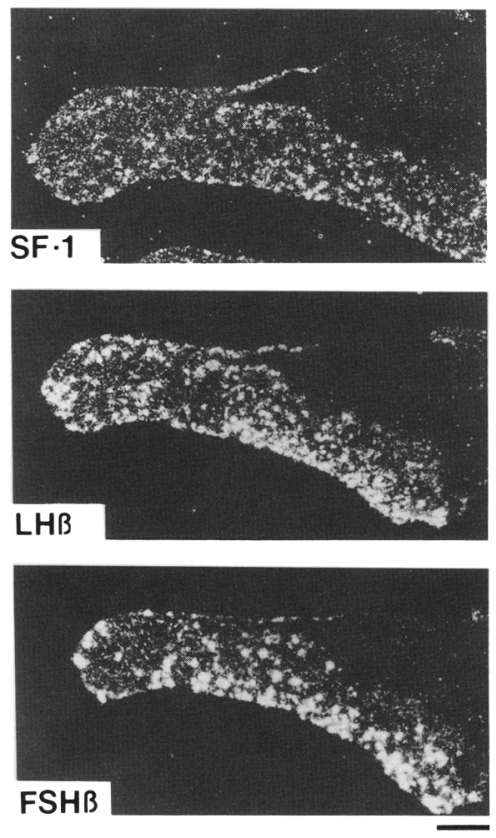

B
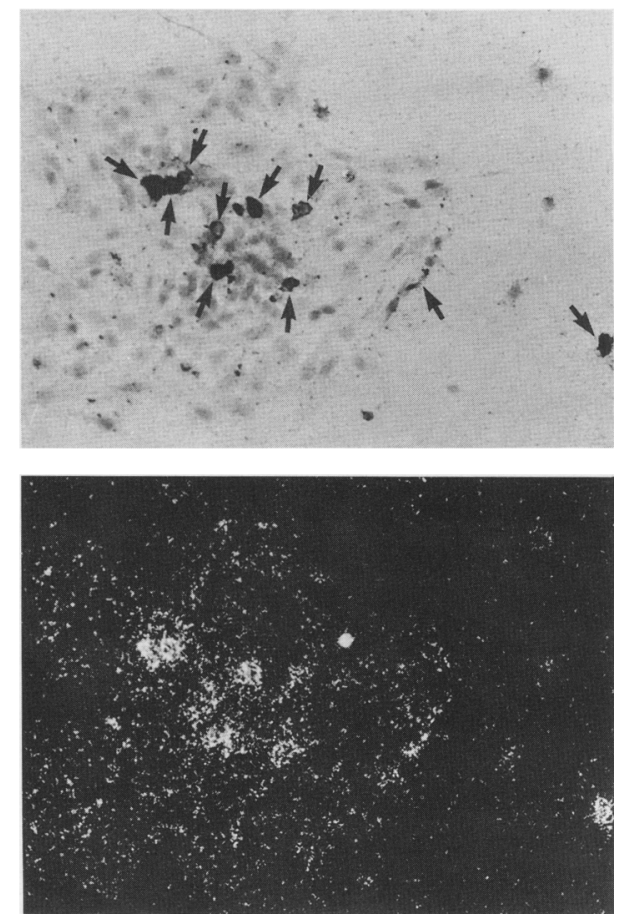

Figure 7. SF-1 colocalizes with gonadotropins. (A) SF-1, LH $\beta$, and FSH $\beta$ transcripts are expressed in very similar patterns in the anterior pituitary. Serial sections of the anterior pituitary from an adult female mouse were analyzed by in situ hybridization with the indicated probes as described in Materials and methods. Dark-field photomicrographs with the SF-1, LH $\beta$, and FSH $\beta$ probes are shown. $(B)$ SF- 1 transcripts and LH immunoreactivity colocalize in primary cultures of rat pituicytes. Primary cultures of rat pituitary cells were prepared and analyzed by combined immunohistochemical analyses with an antiserum specific for $\mathrm{LH}$ and in situ hybridization with an SF-1 cRNA probe as described in Materials and methods. The arrows indicate cells that contain LH immunoreactivity /dark color in bright-field view), which colocalize with silver grains indicative of SF-1 mRNA (bright areas in dark-field view). Bar, 200 $\mu \mathrm{m}(A) ; 50 \mu \mathrm{m}(B)$.
1991). It is unlikely that SF-1 mutations cause this $\mathrm{X}$-linked syndrome because the human homolog of SF-1 maps to chromosome 9 (K. Parker and C. Morton, unpubl.) and Ftz-F1-disrupted mice completely lack gonads, whereas human patients have poorly developed but detectable testes. The striking similarities in these complex endocrine phenotypes nonetheless suggest that SF- 1 and the gene product underlying X-linked adrenal hypoplasia are linked in a common developmental pathway.

Our analyses of Ftz-F1-disrupted mice (this paper; Luo et al. 1994) establish the role of SF-1 in the development and function of multiple endocrine organs that are essential for reproduction. Further identification of genes that act upstream and downstream of SF-1 in the complex events of reproductive organ development and characterization of ligands or coactivators that modulate SF-1 transcriptional effects will undoubtedly provide novel insights into the mechanisms of endocrine differentiation and reproductive function.

\section{Materials and methods}

\section{Materials}

Restriction and modification enzymes were obtained from New England Nuclear (Beverly, MA) or Boehringer Mannheim (Indianapolis, IN). Radionuclides were purchased from New England Nuclear/E.I. DuPont (Boston, MA). Antibodies specific for TSH, $\mathrm{LH}, \mathrm{FSH}, \mathrm{ACTH}$, and GH were provided by Drs. Susan Greenhut and A. F. Parlow through the National Hormone and Pituitary Program. Antibody against human prolactin was purchased from Lipshaw Immunologicals (Pittsburgh, PA). Re- agents for in situ hybridization were purchased from Novagen (Madison, WI). Reagents for immunohistochemical analyses were purchased from Vector Laboratories, Inc. (Burlingame, CA) or Sigma Chemical Co. (St. Louis, MO). The $\alpha \mathrm{T} 3$ cells were provided by Dr. Pamela Mellon (University of California, San Diegol, and the MA-10 cells were provided by Dr. Mario Ascoli (University of Iowa, Iowa City).

\section{Ftz-Fl-disrupted animals}

Mice that are homozygously disrupted at the $F t z-F 1$ locus have been reported recently (Luo et al. 1994). Briefly, a neomycin phosphotransferase selectable marker was inserted within the shared exon encoding the second zinc finger region (Ikeda et al. 1993), thus interfering with function of both the SF-1 and ELP isoforms of Ftz-F1. Ftz-F1 $-/-$ animals were produced by breeding heterozygous $+/-$ animals, which are reproductively intact. The homozygous $-/-$ animals were identified by the absence of adrenals; genotype was confirmed by Southern blotting as described (Luo et al. 1994).

\section{In situ hybridization and immunohistochemistry}

Serial 6- $\mu \mathrm{m}$ sections of dissected pituitaries from wild-type and Ftz-F1-disrupted newborn mice were deparaffinized and hybridized overnight at $50-55^{\circ} \mathrm{C}$ using an in situ hybridization kit according to the recommended protocol. After washes at high stringency, the slides were dipped in Kodak NTB-2 emulsion diluted $1: 1$. Exposure times were 1 week for analyses with the rat $\alpha$ GSU (Godine et al. 1982), mouse POMC (Uhler and Herbert 1983), and rat FSH $\beta$ (Maurer 1987) probes, 3 weeks for the mouse GnRH receptor probe (Tsutsumi et al. 1992), and 4-6 weeks for analyses with the rat LH $\beta$ (Tepper and Roberts 1984) and mouse SF-1 probes (Ikeda et al. 1993). Following exposure, slides were developed in Kodak D-19, fixed, and counterstained 


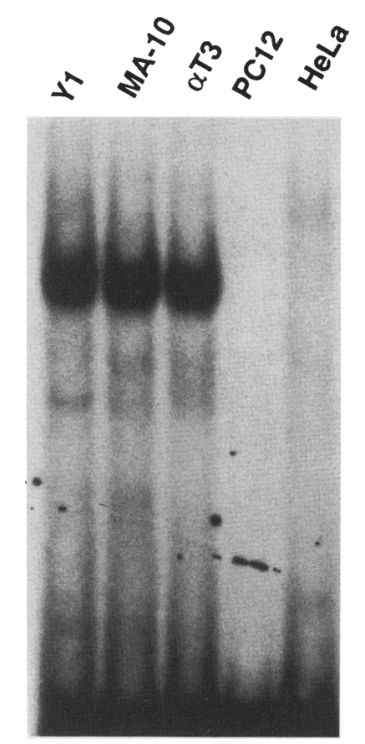

Cell line
Competitor

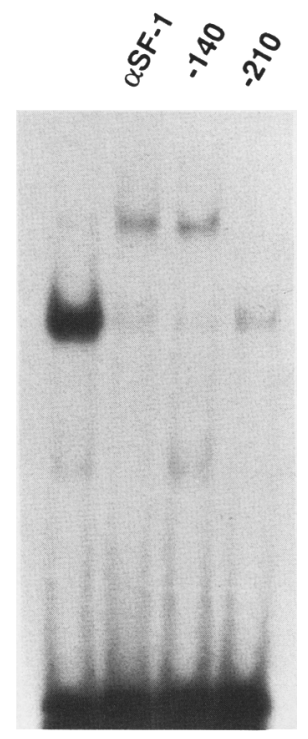

Figure 8. SF-1 is the $\alpha \mathrm{T} 3$ protein that interacts with the GSE. (Left) A GSE-containing complex of similar mobility is formed by Y1 adrenocortical, MA-10 Leydig, and $\alpha \mathrm{T} 3$ gonadotrope nuclear extracts. Nuclear extracts from the indicated tissues were prepared and gel mobility retardation assays with the GSE probe were performed as described in Materials and methods. A prominent complex was seen with $\mathrm{Y} 1, \mathrm{MA}-10$, and $\alpha \mathrm{T} 3$ extracts. (Right) The GSE complex is specifically inhibited by antiserum against SF-1 or by known SF-1-binding sequences. Gel mobility retardation assays with the GSE probe and $\alpha \mathrm{T} 3$ nuclear extracts were performed. Where indicated, extracts were preincubated with unlabeled competitors containing either the 21 -hydroxylase -210 or -140 elements or with antiserum against SF-1 ( $\alpha$ SF-1).

with methyl green. No signals above background were observed with any of the sense probes.

For the GnRH receptor studies, in situ hybridization analyses used a digoxygenin-labeled, 416-nucleotide probe corresponding to a 416-bp PstI-PstI fragment of the mouse GnRH receptor. The plasmid was linearized with EcoRI, and probe was synthesized with T7 RNA polymerase in the presence of digoxygenin11-UTP. After hybridization, the signal was detected by incubating with alkaline phosphatase-coupled anti-digoxygenin antibody (1:1000 dilution), followed by color reaction using nitoblue tetrazolium salt, 5-bromo-4-chloro-3-indol-phosphate toluidinium salt, and levamisol to give blue staining.

In immunohistochemical analyses, paraformaldehyde-fixed, paraffin-embedded $6-\mu \mathrm{m}$ sections were used. The primary antibodies and the dilutions at which they were used included rabbit anti-human ACTH $(1: 4000)$, guinea pig anti-rat $\mathrm{LH}(1: 3000)$, guinea pig anti-rat FSH (1:1000), rabbit anti-rat TSH $(1: 4000)$, monkey anti-rat growth hormone $(1: 15000)$, and rabbit antiPit-1 (1:1500). To detect the peroxidase reaction, a Vectastain $\mathrm{ABC}$ kit was used, except with the anti-growth hormone antibody, where an anti-monkey IgG peroxidase conjugate was purchased from Sigma. Control reactions were performed routinely by substituting normal rabbit serum for the primary antibody.

Colocalization studies combining immunohistochemical analyses with in situ hybridization were performed with primary cultures of rat pituitary cells. Primary cultures of rat pituitary cells were prepared as described (Simmons et al. 1990). Immunohistochemical analyses with the anti-LH and anti-FSH antibodies and in situ hybridization with the SF-1 antisense probe were performed essentially as described above.

\section{Gel mobility retardation assays}

Nuclear extracts were prepared from various cultured cell lines as described (Shapiro et al. 1988). Gel mobility retardation assays with the 21 -hydroxylase -140 and -210 probes were performed as described (Rice et al. 1991), and those with the MIS SF-1-responsive element were done as reported previously (Shen et al. 1994|. The GSE probe contained bases from -222 to -193 of the mouse $\alpha \mathrm{GSU} 5$ '-flanking region, matching the region identified previously as the GSE (Horn et al. 1992), with HindIII ends added to facilitate labeling (top strand, $5^{\prime}$-agctCATAAGCTGTCCTTGAGGTCACCACTACCT-3'). Where indicated, preimmune or immune anti-SF-1 antiserum was added to the binding reaction for $30 \mathrm{~min}$ before addition of probe in the gel mobility retardation assays as described previously (Ikeda et al. 1993). To define the bases required for DNA-protein interaction, we performed gel mobility retardation assays with nuclear extracts from Yl adrenocortical or $\alpha \mathrm{T} 3$ cells and unlabeled oligonucleotide competitors that included either the wild-type 21hydroxylase -140 element or mutations Ml-M7 containing the indicated 2-base alterations of the native sequence (Lala et al. 1992).

\section{Immunoblotting}

Nuclear extracts from various tissues or dissected pituitaries were resolved by SDS-PAGE, transferred to a nitrocellulose membrane by electroblotting, preincubated for $1 \mathrm{hr}$ in TBS, $1 \%$ Tween-20, and $5 \%$ nonfat dry milk, and washed repeatedly in the same buffer containing $1 \%$ milk. The filter was incubated overnight at $4^{\circ} \mathrm{C}$ with rabbit anti-SF-1 polyclonal antibody $\{1$ : 5000 dilution), washed, and incubated for $1 \mathrm{hr}$ with the secondary antibody (goat anti-rabbit horseradish peroxidase conjugate, 1: 3000 dilution). After washing, the blot was developed with a Chemiluminescence kit (New England Nuclear-DuPont) and exposed to Kodak X-Omat film.

\section{RNase protection assays}

RNase protection assays with the rat SF-1 probe were performed as described previously (Shen et al. 1994), with minor modifications. The rat SF-1 cRNA probe was generated by linearizing the partial rat SF-1 cDNA (Lynch et al. 1993) with NcoI and transcribing with an RNA transcription kit (Stratagene) and T3 polymerase (Promega). The probe was gel purified and precipitated, and $500,000 \mathrm{cpm}$ of the labeled probe was mixed with 5 $\mu \mathrm{g}$ of RNA samples, denatured at $95^{\circ} \mathrm{C}$, and hybridized overnight at $55^{\circ} \mathrm{C}$. Samples were digested in a $330-\mu$ l volume with $10 \mu \mathrm{g}$ of RNase A (Sigma) and $0.5 \mu \mathrm{g}$ of RNase T1 (Boehringer Mannheim) for $60 \mathrm{~min}$ at $37^{\circ} \mathrm{C}$, treated with $20 \mu \mathrm{g}$ of proteinase $\mathrm{K}$ (Boehringer Mannheim) in the presence of carrier tRNA, and analyzed on a $6 \% 0.5 \times$ TBE denaturing polyacrylamide gel. Total RNA was isolated as described (Moore et al. 1990).

For experiments with the GnRH receptor, a plasmid containing a 592-bp HindIII-HindIII fragment of the mouse GnRH receptor (Tsutsumi et al. 1992) was linearized with StuI and extended with $\mathrm{T} 7$ polymerase to generate a 534-nucleotide antisense probe containing 434 nucleotides of GnRH receptor sequence. This probe was used in RNase protection assays with 
total pituitary RNA $(10 \mu \mathrm{g})$ prepared from $+/+,+/-$, and $-1-$ mice and an RNase protection kit purchased from Ambion (Austin, TX). The integrity of the RNAs was confirmed by RNase protection assays with a probe for mouse $\beta$-actin supplied with the kit.

\section{Acknowledgments}

We thank Dr. Beverly Koller and Ann Latour for invaluable help in producing the Ftz-F1-disrupted mice and Gina Apicelli and Jeana Meade for technical assistance. We thank Drs. Bernard Schimmer, Rudolf Grosschedl, Sally Camper, Malcolm Low, Istvan Merchenthaler, and Richard Weiner for helpful discussions and careful reading of the manuscript. We thank Drs. Mario Ascoli, James Roberts, Stuart Sealfon, Kevin Catt, William Chin, Philip Smith, A. F. Parlow, Bruce White, Richard Maurer, Betty Eipper, and Pamela Mellon for providing reagents used in these experiments. Dr. Gloria S. Tannenbaum kindly performed the radioimmunoassays for growth hormone. This work was supported by the Howard Hughes Medical Institute and National Institutes of Health (NIH) grant HL48460 (to K.L.P.), and the NIH, the March of Dimes Foundation, and the Lucille Markey Charitable Trust (to H.A.I.), and the NIH (to J.H.N.).

\section{Note added in proof}

Barnhart and Mellon (1994) have also reported that SF-1 is the GSEB (Barnhart et al., Endocrinol. 8: 878-885).

\section{References}

Akerblom, I.E., E.C. Ridgeway, and P.L. Mellon. 1990. An $\alpha$-subunit-secreting cell line derived from a mouse thyrotrope tumor. Mol. Endocrinol. 4: 589-596.

Bodner, M. J.-L. Catrillo, L.E. Theill, T. Deerinck, M. Elisman, and M. Karin. 1988. The pituitary-specific transcription factor, GHF-1 is a homeobox-containing protein. Cell 55: 505518.

Charlton, H.M., D.M. Halpin, C. Iddon, R. Rosie, G. Levy, I.F. McDowell, A. Megson, J.F. Morris, A. Bramwell, A. Speight, B.J. Ward, J. Broadhead, G. Davey-Smith, and G. Fink. 1983. The effects of daily administration of single and multiple injections of gonadotropin-releasing hormone on pituitary and gonadal function in the hypogonadal (hpg) mouse. Endocrinology 113: 535-544.

Gharib, S.D., M.E. Wierman, M.A. Shupnik, and W.W. Chin. 1990. Molecular biology of the pituitary gonadotropins. Endocrinol. Rev. 11: 177-199.

Godine, J.E., W.W. Chin, and J.F. Habener. 1982. Alpha subunit of rat pituitary glycoprotein hormones. Primary structure of the precursor determined from the nucleotide sequence of cloned cDNAs. I. Biol. Chem. 257: 8368-8371.

Hamernik, D.L., R.A. Keri, C.M. Clay, I.N. Clay, G.B. Sherman, H.R. Sawyer, Jr., T.M. Nett, and J.H. Nilson. 1992. Gonadotrope-and thyrotrope-specific expression of the human and bovine glycoprotein hormone alpha-subunit genes is regulated by distinct cis-acting elements. Mol. Endocrinol. 6: $1745-1755$.

Honda, S.-I., K.-I. Morohashi, M. Nomura, H. Takeya, M. Kitajima, and T. Omura. 1993. Ad4BP regulating steroidogenic $\mathrm{P}-450$ gene is a member of steroid hormone receptor superfamily. J. Biol. Chem. 268: 7494-7502.

Horn, F., J.J. Windle, K.M. Barnhart, and P.L. Mellon. 1992. Tissue-specific gene expression in the pituitary: The glycopro- tein hormone $\alpha$-subunit gene is regulated by a gonadotropespecific protein. Mol. Cell. Biol. 12: 2143-2153.

Ikeda, Y., D.S. Lala, X. Luo, E. Kim, M.-P. Moisan, and K.L. Parker. 1993. Characterization of the mouse FTZ-F1 gene, which encodes an essential regulator of steroid hydroxylase gene expression. Mol. Endocrinol. 7: 852-860.

Ikeda, Y., W.-H. Shen, H.A. Ingraham, and K.L. Parker. 1994. Developmental expression of mouse steroidogenic factor 1, an essential regulator of the steroid hydroxylases. Mol. Endocrinol. 8: 654-662.

Ingraham, H.A., R.P. Chen, H.J. Mangalam, H.P. Elsholtz, S.E. Flynn, C.R. Lin, D.M. Simmons, L.W. Swanson, and M.G. Rosenfeld. 1988. A tissue-specific transcription factor containing a homeodomain specifies a pituitary phenotype. Cell 55: 519-529.

Japon, M.G., M. Rubinstein, and M.J. Low. 1994. In situ hybridization analysis of anterior pituitary hormone gene expression during fetal mouse development. J. Histochem. Cytochem. 42: 1117-1125.

Kendall, S.K., T.L. Saunders, L. Jin, R.V. Lloyd, L.M. Glode, T.M. Nett, R.A. Keri, J.H. Nilson, and S.A. Camper. 1991. Targeted ablation of pituitary gonadotropes in transgenic mice. Mol. Endocrinol. 5: 2025-2036.

Kletter, G.B., J.L. Gorski, and R.P. Kelch. 1991. Congenital adrenal hypoplasia and isolated gonadotropin deficiency. Trends Endocrinol. Metab. 2: 123-128.

Lala, D.S., D.A. Rice, and K.L. Parker. 1992. Steroidogenic factor l, a key regulator of steroidogenic enzyme expression, is the mouse homolog of fushi tarazu-factor 1. Mol. Endocrinol. 6: $1249-1258$.

Lew, D., H. Brady, K. Klausing, K. Yaginuma, L.E. Theill, C. Stauber, M. Karin, and P.L. Mellon. 1993. GHF-1-promotertargeted immortalization of a somatotropic progenitor cell results in dwarfism in transgenic mice. Genes \& Dev. 7: 683-693.

Li, S., E.B.I. Crenshaw, E.J. Rawson, D.M. Simmons, L.W. Swanson, and M.G. Rosenfeld. 1990. Dwarf locus mutants lacking three pituitary cell types result from mutations in the POUdomain gene pit-1. Nature 347: 528-533.

Luo, X., Y. Ikeda, and K.L. Parker. 1994. A cell-specific nuclear receptor is essential for adrenal and gonadal development and sexual differentiation. Cell 77: 481-490.

Lynch, J.A., D.S. Lala, J.J. Pelusco, W. Luo, K.L. Parker, and B. White. 1993. Steroidogenic factor 1 (SF-1), an orphan nuclear receptor, regulates the expression of the rat aromatase gene in gonadal tissues. Mol. Endocrinol. 7: 776-786.

Mason, A.J., J.S. Hayflick, R.H. Zoeller, W.S. Young III, H.S. Phillips, K. Nikolics, and P. Seeburg. 1986. A deletion truncating the gonadotropin-releasing hormone gene is responsible for hypogonadism in the hpg mouse Science 234: 13661371.

Maurer, R.A. 1987. Molecular cloning and nucleotide sequence analysis of complementary deoxyribonucleic acid for the $\beta$-subunit of rat follicle stimulating hormone. Mol. Endocrinol. 1: 717-723.

Mellon, P.L., J.J. Windle, P.C. Goldsmith, C.A. Padula, J.L. Roberts, and R.I. Weiner. 1990. Immortalization of hypothalamic GnRH neurons by genetically targeted tumorigenesis. Neuron 5: 1-10.

Moore, C.C.D., S. Brentano, and W.L. Miller. 1990. Human P450SCC gene transcription is induced by cyclic AMP and repressed by 12-o-tetradecanoyl phorbol-13 acetate and A23187 through independent cis elements. Mol. Cell. Biol. 10: 6013-6023.

Morohashi, K., S. Honda, Y. Inomata, H. Handa, and T. Omura. 1992. A common trans-acting binding factor, Ad4-binding 
Ingraham et al.

protein, to the promoters of steroidogenic P-450s. I. Biol. Chem. 267: 17913-17919.

Peschon J.J., R.R. Behringer, R.L. Cate, K.A. Harwood, R.L. Idzerda, R.L. Brinster, and R.D. Palmiter. 1992. Directed expression of an oncogene to Sertoli cells in transgenic mice using Müllerian inhibiting substance regulatory sequences. Mol. Endocrinol. 6: 1403-1411.

Pierce, J.D. and R.F. Parsons. 1981. Glycoprotein hormones: Structure and function. Annu. Rev. Biochem. 50: 465-495.

Pfäffle, R.W., G.E. DiMattia, J.S. Parks, M.R. Brown, J.M. Wit, M. Jansen, H. Van der Nat, J.L. Van den Brande, M.G. Rosenfeld, and H.A. Ingraham. 1992. Mutation of the POU-specific domain of Pit-1 and hypopituitarism without pituitary hypoplasia. Science 257: 1118-1121.

Rice, D.A., A.R. Mouw, A. Bogerd, and K.L. Parker. 1991. A shared promoter element regulates the expression of three steroidogenic enzymes. Mol. Endocrinol. 5: 1552-1561.

Roberson, M.S., W.E. Schoderbek, G. Tremml, and R.A. Maurer. 1994. Activation of the glycoprotein hormone $\alpha$ subunit promoter by a LIM-homeodomain transcription factor. Mol. Cell. Biol. 14: 2985-2993.

Schwanzel-Fukuda, M., K.L. Jorgenson, H.T. Bergen, G.D. Weesner, and D.W. Pfaff. 1992. Biology of normal luteinizing hormone-releasing hormone neurons during and after their migration from olfactory placode. Endocr. Rev. 13: 623-634.

Shapiro, D.J., P.A. Sharp, W.W. Wahli, and M.J. Keller. 1988. A high-efficiency HeLa cell nuclear transcription extract. DNA 7: 47-55.

Shen, W.-H., C.C.D. Moore, Y. Ikeda, K.L. Parker, and H.A. Ingraham. 1994. The nuclear receptor SF-1 regulates MIS gene expression: Links to the sex determination pathway. Cell 77: 651-661.

Simmons, D.M., J.W. Voss, H.A. Ingraham, J.M. Holloway, R.S. Broide, M.G. Rosenfeld, and L.W. Swanson. 1990. Pituitary cell phenotypes involve cell-specific Pit-1 mRNA translation and synergistic interactions with other classes of transcription factors. Genes \& Dev. 4: 695-711.

Tepper, M.A. and J.L. Roberts. 1984. Evidence for only one $\beta$-luteinizing hormone and no $\beta$-chorionic gonadotropin gene in the rat. Endocrinology 115: 385-391.

Theill, L.E. and M. Karin. 1993. Transcriptional control of growth hormone expression and anterior pituitary development. Endoc. Rev. 14: 670-689.

Thorner, M.O., M.L. Vance, E. Horvath, and K. Kovacs. 1992. The anterior pituitary. In William's textbook of endocrinology, 8th ed. (ed. J.D. Wilson and D.W. Foster), pp. 221-310. W.B. Saunders Co., Philadelphia, PA.

Tsutsumi, M., W. Zhou, R.P. Millar, P.L. Mellon, J.L. Roberts, C.A. Flanagan, K. Dong, B. Billo, and S.C. Sealfon. 1992. Cloning and functional expression of a mouse gonadotropinreleasing hormone. Mol. Endocrinol. 6: 1163-1169.

Uhler, M. and E. Herbert. 1983. Complete amino acid sequence of mouse pro-opiomelanocortin derived from the nucleotide sequence of pro-opiomelanocortin cDNA. I. Biol. Chem. 258: $257-261$.

Voss, J.W. and M.G. Rosenfeld. 1992. Anterior pituitary development: Short tales from dwarf mice. Cell 70: 527-520.

Windle, J.J., R.I. Weiner, and P.L. Mellon. 1990. Cell lines of the pituitary gonadotrope lineage derived by targeted oncogenesis in transgenic mice. Mol. Endocrinol. 4: 597-603. 


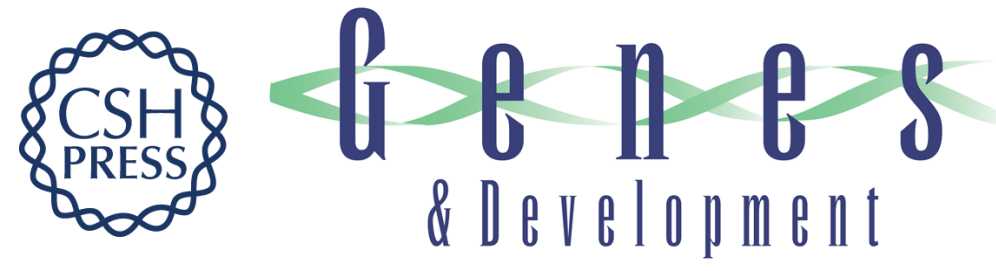

\section{The nuclear receptor steroidogenic factor 1 acts at multiple levels of the reproductive axis.}

H A Ingraham, D S Lala, Y Ikeda, et al.

Genes Dev. 1994, 8:

Access the most recent version at doi:10.1101/gad.8.19.2302

References This article cites 39 articles, 11 of which can be accessed free at:

http://genesdev.cshlp.org/content/8/19/2302.full.html\#ref-list-1

License

Email Alerting Receive free email alerts when new articles cite this article - sign up in the box at the top Service right corner of the article or click here.

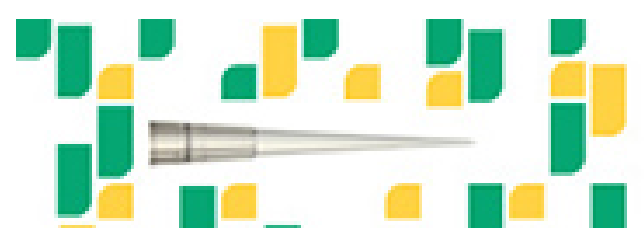

Focused on your science.

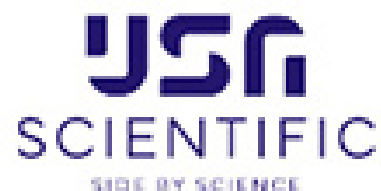

Copyright (c) Cold Spring Harbor Laboratory Press 